Case report

\title{
Acute coronary syndrome after coronary subclavian steal syndrome treatment综次谉
}

\author{
Belma Kalaycl ${ }^{\text {a,* }}$, Süleyman Kalaycl ${ }^{\text {b }}$ \\ a Bülent Ecevit University Hospital, Department of Cardiology, MD, 61600 Zonguldak, Turkey \\ b Zonguldak Atatürk State Hospital, MD, Zonguldak, Turkey
}

\section{A R T I C L E I N F O}

\section{Article history:}

Received 2 November 2016

Accepted 30 December 2016

Available online 3 January 2017

\begin{abstract}
A B S T R A C T
Left subclavian artery stenosis can be a cause of recurrent angina after coronary artery bypass grafting in patients with a coronary steal. These patients may suffer claudication in the left arm and angina pectoris when using their left arm. The subclavian artery shows retrograde filling with use of a left internal mammary artery graft, which can cause coronary ischemia depending on blood flow. This is a report of a patient who presented with coronary subclavian steal syndrome and underwent percutaneous implantation of a stent in the left subclavian artery. However, the patient was readmitted with acute coronary syndrome 1 year later. An angiogram showed an unexpected decrease in anterograde flow in the left internal mammary artery graft after stenting the subclavian artery.

(c) 2016 The Society of Cardiovascular Academy. Production and hosting by This is an open access article under the CC BY-NC-ND license (http://creativecommons.org/licenses/by-nc-nd/4.0/)
\end{abstract}

\section{Introduction}

Left subclavian artery stenosis is a cause of recurrent angina after coronary artery bypass grafting (CABG) in patients with coronary steal syndrome. The patients can suffer claudication in the left arm and angina pectoris when using their left arm. The subclavian artery shows retrograde filling when a left internal mammary artery (LIMA) graft is used, which can cause coronary ischemia depending on blood flow. Herein, we report a case of coronary subclavian steal syndrome (CSSS) in a male patient who underwent percutaneous implantation of a stent into the left subclavian artery. However, the patient was re-admitted with acute coronary syndrome 1 year later. Angiography showed an unexpected decrease in anterograde flow in the LIMA graft after stenting the subclavian artery.

Recurrent angina can occur as a result of atherosclerotic progression of coronary lesions after CABG. ${ }^{1}$ Left subclavian artery stenosis

\footnotetext{
it Peer review under responsibility of The Society of Cardiovascular Academy. 论 Not: Bu olgu sunumu daha önce Anadolu kardiyoloji dergisine ve wiener klinische wochenschrift dergisine gönderildi. Fakat kabul edilmedi. Herhangi bir kongrede tebliğ edilmedi.

* Corresponding author.

E-mail addresses: drbelma@hotmail.com (B. Kalaycı),dr_suleyman_kalayci@ yahoo.com (S. Kalaycı).
}

proximal to the LIMA graft is a rare and critical cause of angina following CABG. Therefore, CSSS should be considered in patients with claudication in the left arm and angina pectoris when using their left arm. Retrograde filling may result from circulation from the LIMA to the left subclavian artery depending on the coronary blood flow and may cause myocardial ischemia and thereby CSSS eventually.

\section{Case report}

A 57-year-old male smoker with hypertension and a history of coronary artery disease was admitted to our clinic. He had undergone CABG 7 years previously. He was being re-admitted for angina pectoris and a painful left arm when in use, particularly when carrying bags. The angina had progressively worsened, occurring during mild efforts and posing some limitations on his daily activities, but it resolved with rest. The patient was not suspected of having arm paresthesia. Physical examination findings were normal except a distinct difference in blood pressure (i.e., $20 \mathrm{mmHg}$ ) between the two arms. Electrocardiography, echocardiography, and laboratory studies were unremarkable on admission. Coronary angiography and bypass graft imaging revealed mild to moderate coronary stenosis in the mid-region of the left anterior descending (LAD) artery and retrograde filling of the LIMA bypass. Retrograde flow in the LIMA graft was revealed by angiography obtained from the LAD artery to the left subclavian and left vertebral artery (Fig. 1). The saphenous vein graft to the left circumflex artery and right coronary artery 


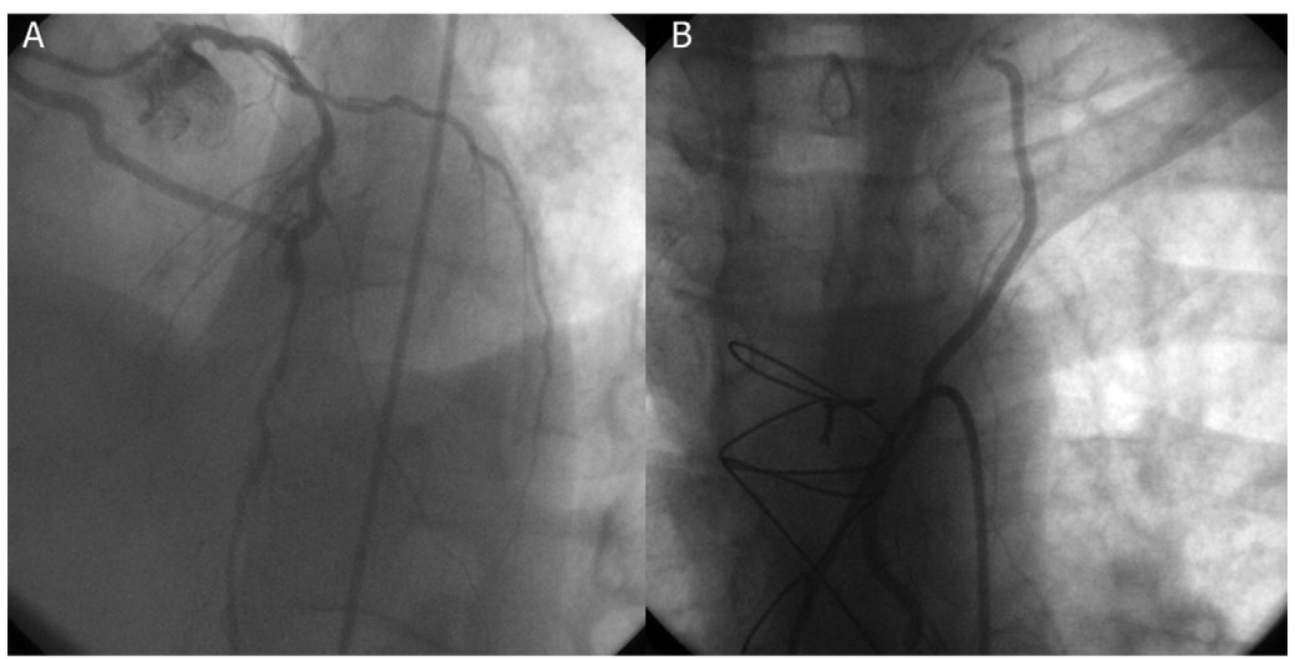

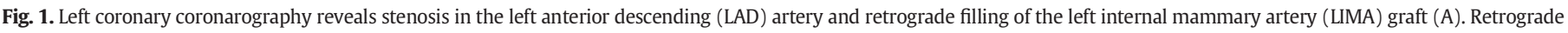
flow from the LAD to left subclavian and left vertebral arteries (B).

was nearly normal. Significant stenosis of the left subclavian artery proximal to the origin of the LIMA was detected by angiography (Fig. 2). Based on these findings, we recommended percutaneous treatment. However, the patient rejected treatment. A percutaneous stent was implanted into the left subclavian artery 1 month later at another clinic. Clopidogrel was added to his treatment regimen. The patient had an uneventful course following stent implantation but was admitted to the emergency department 1 year later with unstable angina. Coronary angiography revealed reduced retrograde flow in the LIMA from the LAD artery (Fig. 3A). Anterograde flow in the LIMA was also reduced unexpectedly as a result of flow competition between the LAD artery and LIMA (Fig. 3B). Subclavian angiography revealed a patent subclavian artery stent. As a

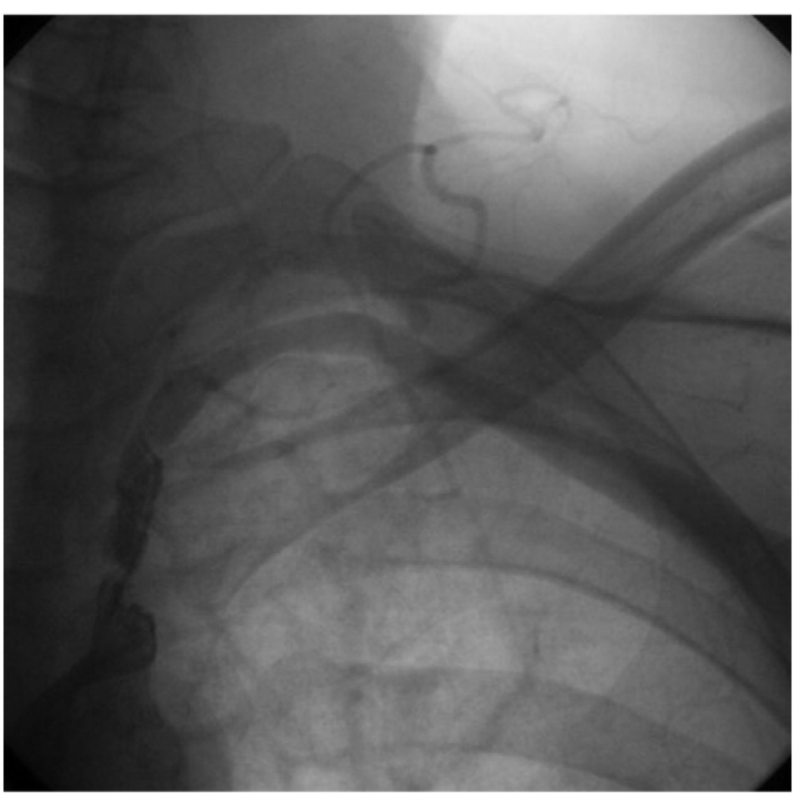

Fig. 2. Severe subclavian artery stenosis before stenting. result, the patient was scheduled for follow-up visits under pharmacological therapy.

\section{Discussion}

CSSS is defined by a reversal of coronary flow in the LIMA caused by proximal subclavian artery stenosis., ${ }^{2,3}$ The incidence of CSSS is about $0.2 \%$ to $0.68 \%$ of patients referred for CABG with LIMA. Its diagnosis is determined easily by angiography. ${ }^{3}$ Symptoms have been reported to occur between 2 and 31 years following CABG surgery. ${ }^{4}$ The clinical spectrum of CSSS is broad and includes stable angina, silent ischemia, or acute coronary syndrome ${ }^{6,7}$.

Reversed flow in the subclavian artery is usually part of the cause of significant stenosis in the LAD artery. However, flow may rarely reach the subclavian artery because of the blood flow from the native vessel and the peripheral vascular resistance of the subclavian artery. ${ }^{6}$ As a result, myocardial ischemia may develop upon use of the left arm as a result of a blood flow shift from the LAD artery to the subclavian artery. These patients are often admitted with stable angina. However, they may also present with acute coronary syndrome ${ }^{7,8}$.

The treatment for CSSS is revascularization of the subclavian artery. The subclavian artery and anterograde LIMA flow may increase following a successful subclavian angioplasty. ${ }^{3}$ However the restenosis rate for angioplasty is reported to be as high as $40.7 \%$ over 5 years in patients with CSSS. ${ }^{5}$ Besides the anterograde flow in the LIMA graft may decrease following percutaneous treatment of the competing flow.

Acute coronary syndrome was diagnosed for multiple reasons in our case. One possible mechanism is plaque destabilization in the native coronary, subclavian artery, or coronary grafts with distal microembolization. Endothelial dysfunction or microvascular disease may also cause unstable angina. ${ }^{2}$ Another mechanism is increased peripheral vascular resistance of the subclavian artery following angioplasty, as in our case.

In conclusion, CSSS can be treated successfully by subclavian angioplasty. However, these patients may encounter recurrent cardiac events due to diffuse atherosclerotic plaques. They may be admitted with acute coronary syndrome following percutaneous treatment. The culprit lesion was a challenge to identify in the present case. 


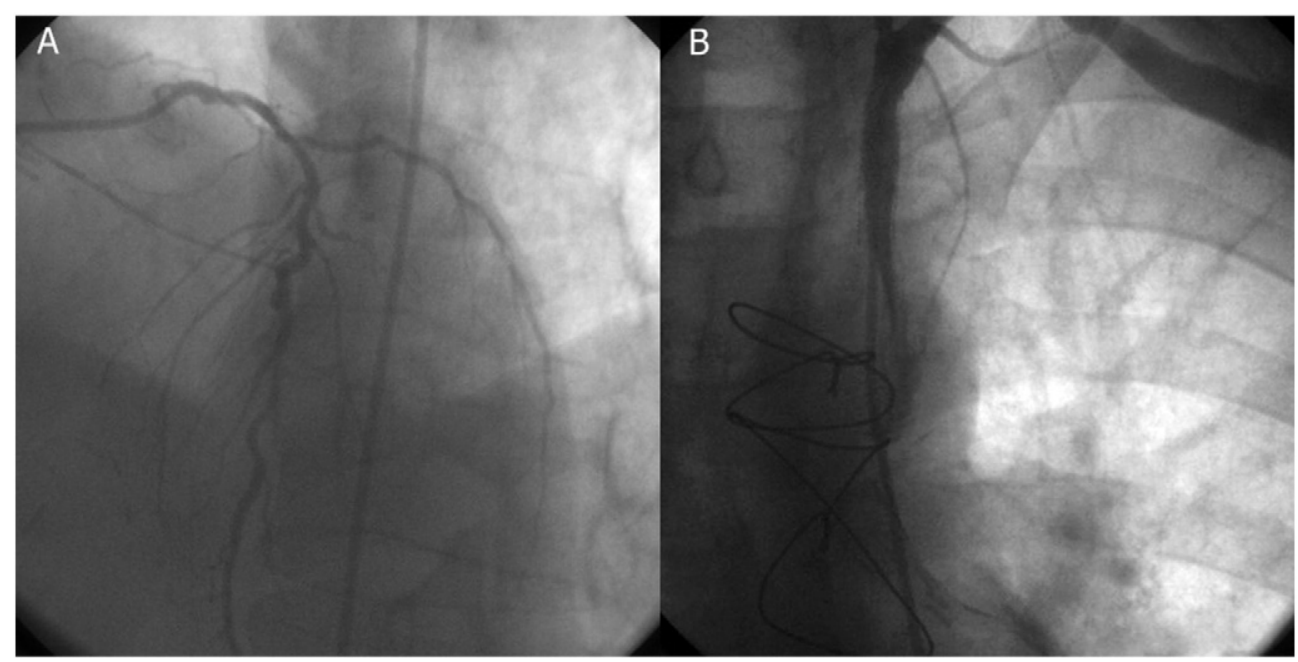

Fig. 3. Subclavian artery (A) and decreased anterograde blood flow in the left internal mammary artery (LIMA) after stenting the subclavian artery (B).

Although the subclavian stent was patent, the LIMA graft was recognized as the culprit lesion.

\section{Declaration of conflicting interests}

The authors declared no conflicts of interest with respect to the authorship and/or publication of this article.

\section{References}

1. Rezende PC, da Costa LM, Scudeler TL, Nakamura D, Giorgi MC, Hueb W. Recurrent angina caused by coronary subclavian steal syndrome confirmed by positron emission tomography. Ann Thorac Surg 2015;99(5):e111-e114.

2. Lelek M, Bochenek T, Drzewiecki J, Trusz-Gluza M. Unstable angina as a result of coronary-subclavian steal syndrome. Circ Cardiovasc Interv 2008;1(1):82-84.
3. Pappy R, Kalapura T, Hennebry TA. Anterolateral myocardial infarction induced by coronary-subclavian-vertebral steal syndrome successfully treated with stenting of the subclavian artery. J Invasive Cardiol 2007;19(8):E242-E245.

4. Westerband A, Rodriguez JA, Ramaiah VG, Diethrich EB. Endovascular therapy in prevention and management of coronary-subclavian steal. J Vasc Surg 2003;38(4): 699-704.

5. Paraskevaidis SA, Giavroglou KE, Proios TD, Saratzis NA, Louridas GE. Stent implantation at subclavian artery in a patient with left internal mammary graft and subclavian steal syndrome. Hell J Cardiol 1997;38(4):310-315.

6. Marc M, Iancu A, Molnar A, Bindea D. Coronary-subclavian steal: case series and review of the literature. Clujul Med. (1957) 2015;88(1):79-82.

7. Tan JW, Johan BA, Cheah FK, Wong P. Coronary subclavian steal syndrome: a rare cause of acute myocardial infarction. Singap Med J 2007:48(1):e5-e8.

8. Iglesias JF, Degrauwe S, Monney P, et al. Coronary subclavian steal syndrome and acute anterior myocardial infarction: a new treatment dilemma in the era of primary percutaneous coronary intervention. Circulation 2015;132(1):70-71. 